\title{
20. Philosophical reflections on the concept of innovation
}

\author{
Vincent Blok
}

\section{INTRODUCTION}

Innovation is often uncritically seen as a good thing (Rogers 1976) and considered as a panacea for all kinds of socio-economic challenges (Blok and Lemmens 2015). At the same time, the concept of innovation itself remains undefined in most policy documents, while its meaning seems to be taken for granted in the scientific literature (Godin 2015). We are familiar for instance with dichotomies like incremental versus disruptive innovation (Christensen 1997) or closed versus open innovation (Chesbrough 2003, 2006), but what does the notion of innovation itself mean? While it is nowadays often understood as the commercialization of technological inventions (von Schomberg and Blok 2018), new developments like the emergence of social, sustainable and responsible innovation make this self-evident conceptualization questionable. If we do not confront this self-evident understanding of innovation, as it is found in economics, innovation studies and business administration, the conceptualization of these new developments remain hemmed in by traditional innovation philosophies.

One would expect that the philosophical tradition can provide guidance in our understanding of innovation, as philosophers traditionally reflect on basic concepts and categories that structure our understanding of the world, such as nature versus technology, humans versus non-humans and so on. It is striking, however, that the notion of innovation is not among the key concepts that traditional philosophers tend to reflect upon (Blok 2020, 2021). One reason might be that philosophers originally tend to understand and gain knowledge of the world around us, rather than to change or innovate it. Further, the object of philosophical knowledge is traditionally found beyond the world of becoming in which innovations take place, and aims at knowledge about the non-changing or universal categories that underlie this world of becoming, for instance knowledge about the Platonic ideas or the Kantian categories. Finally, to the extent that the primary objective of philosophical knowledge is to understand the world, traditional philosophers may have the tendency to conform themselves to the world as it is, rather than changing or revolutionizing it. Nonetheless, to the extent that philosophical reflection can contribute to the critical assessment of basic concepts, and innovation is one of the concepts that mark our time, we take a step back in this chapter and philosophically reflect on the notion of innovation. Such a philosophy of innovation enables us to critically reflect on the self-evidence of the techno-economic paradigm of innovation and its applicability on contemporary phenomena like social and sustainable innovation.

In order to open up the phenomenon of innovation, we distinguish between the innovation process and outcome dimension, and between the ontic and ontological dimension of innovation (section 1). The ontic dimension of innovation concerns beings like new artefacts, and the ontological dimension concerns the being of these beings. These distinctions lead to four characteristics of our understanding of innovation with several implications for the object of 
innovation and its novelty, as well as for the temporality and human involvement in innovation practices. It will turn out that innovation concerns the ontogenetic process in which primarily a world is constituted - that is, the digital world - in which the invention of new artefacts - that is, blockchain technology - is embedded. ${ }^{1}$ This ontogenetic process doesn't follow a chronological temporal order, but is constituted by a temporal iterative process. Human creativity is involved in this ontogenetic process as co-creative capacity (section 2). In section 3, we show the advantage of our conceptualization of innovation and its implications for contemporary and future alternative theories of innovation.

\section{PHILOSOPHY OF INNOVATION ${ }^{2}$}

In this section, we subsequently discuss (a) the innovation process and outcome dimension, and (b) the ontic and ontological dimension of innovation, which leads to four characteristics of the phenomenon of innovation.

\section{(a) The Process and Outcome Dimension of Innovation}

A first characteristic of innovation can be found if we oppose the innovation process to the outcome of the process. The word innovation has both a substantive meaning, for example the iPhone as an outcome or end-product - and a verbal meaning - the innovation process that results in the iPhone as outcome. On the one hand, this innovation outcome may be considered as something new to the world, for instance the first time Apple introduced the iPhone as an outcome or end-product of the innovation process. On the other hand, the creation of this new end-product will replace predecessors of the smartphone, for instance the dominance of landlines in Western households. Because innovation is not only an outcome but also a process, it is something that can and should be managed. Stage gate models (Cooper 2008) and technology readiness levels of innovation for instance enable the management of this innovation process in such a way that it leads to the best possible outcomes.

In economic thinking, the process of innovation is often understood in terms of a creative destruction; the innovation of the diesel engine in locomotives for instance is not only the creation of a new end-product that can be exchanged on the market, but destructed at the same time the existing industry in steam engines, just like the innovation of the compact disc destructed the industry of cassette tapes and LPs and is now replaced by streaming services (Schumpeter 1943; Blok 2020). But we do not have to refer to Schumpeter's concept of creative destruction to understand the dynamic process of creation and destruction involved in the innovation process. The history of the concept of innovation shows that it always appeared in the context of a dominant "paradigm of orthodoxy, authority and order" (Godin 2015, p. 93). Innovations involve something new that intervenes within the established order. Plato for instance introduces the concept of innovation in the context of the political order. $\mathrm{He}$ argues against innovation because it introduces change that threatens the established political order (Plato 1967; Aristotle 1944; Blok 2020). How do we have to understand this dynamic innovation process that creates something new and at the same time threatens to undermine or destruct the existing order?

If we consider the outcome of the innovation process as a concrete individual object or artefact, the innovation process itself can be formally conceived as the pre-individual. This 
reality of the innovation process before its individuation in a concrete innovation outcome can be conceptualized as the ontogenesis of this outcome. Ontogenesis originally refers to the developmental processes and conditions for the development of an individual organism, from the time of fertilization to its mature form, but can be found in the development of innovations as well. The reality of the ontogenetic process of innovation cannot be understood out of its outcome, like incremental and radical innovation, or closed and open innovation, because then the process of innovation is conceptualized based on its outcome, that is, the pre-individual is understood in terms of the individual that comes out of it and not out of this process itself. Precisely this is the problem with many typologies of innovation in the innovation management literature. Although the process of innovation is theorized since the 1920s in disciplines like anthropology and sociology, distinctions like incremental versus radical innovation (Freeman and Soete 1997) or architectural versus modular innovations (Henderson and Clark 1990) characterize different types of innovations but miss its ontogenetic process. On the contrary, the outcomes of the innovation process - concrete individual products or services, its components or the compositions of these components - are taken as point of departure. This focus on the innovation outcome may be explained by what is called the 'culture of things' or material culture: "The origin of this culture goes back to the Renaissance: due to commercial exchanges, exploration and travel, natural and artificial objects have been what is valued in arts, science, and real life" (Godin 2008, p. 21). But if innovation concerns both the process and the outcome of the process, a philosophical reflection can no longer be isolated to outcomes, but must come to terms with the process that is a distinct and integral part of innovation. On the one hand, if we find the point of departure of our reflections in the outcome of the innovation process - that is, the artefact as outcome of innovation - we miss the operation that is constituting this innovative outcome, we miss innovation as an ontogenetic process. On the other hand, if we find the point of departure of our reflection in the process of the creation of the innovation outcome that at the same time threatens to destruct the established order, we should no longer think the ontogenetic process out of an individual innovation outcome that is created while it destructs a previous individual outcome. On the contrary, it should be understood out of the process of creation and destruction itself, that is, at the pre-individual level. With this, we assume a fundamental difference between outcome and process, between individual and pre-individual, thereby keeping open the possibility that innovation as process cannot be reduced to innovation as outcome, which is to say that process and outcome are divided by a fundamental difference. We shouldn't take this as an invitation to disregard the innovation outcome - it is highly questionable whether we can understand innovations without taking this outcome into consideration, for instance because these outcomes only account for spatio-temporal differences of their manifestation - but rather as a call to acknowledge both outcome and ontogenetic process as two fundamental aspects of innovation.

This acknowledgement of the ontogenetic process of innovation has certain advantages over established conceptualizations that find their point of departure in either the human creation as input of the innovation process or in the artefact as output of the process. It enables the analysis of general patterns in the ontogenesis of innovation, like the process of concretization in which innovations initially form an abstract system of isolated parts that function separately - for instance a cell-phone with a separate screen and key-board - but becomes increasingly integrated and perfected - for instance the integration of screen and key-board in modern smartphones - that cannot be attributed to the subject or object of innovation, but may be associated with the ontogenesis of the innovation process as such (see Simondon 2017). 
At the level of the innovation outcome, a second difference emerges if we consider that innovations involve something new that intervenes with the established order. If Plato for instance argues against innovation because it introduces change in the political order, he is not interested in the creative destruction of an individual artefact, but in the political order of the world that is threatened by innovation and potentially replaced by a new political order.

The dynamic nature of this creation and destruction of the political order becomes clear if we ask for the measure or unity of the order of the world. The philosophical tradition starting with Plato finds this measure or unity in the ontological characteristic of the being of beings, that is, in the transcendental horizon of the Platonic idea. The idea is a fixed category or measure, within which the world appears as an ordered whole that makes sense. In light of the idea 'human being' for instance, various people appear as human beings and we can understand this variety of humans as human beings. The idea human being is itself not a human being, but concerns a given measure, category or value within which the variety of people appears as unity. In the philosophical tradition there is a fundamental difference between the $i d e a$, category or value that establishes the order of beings in the world, and these beings themselves, which can only be perceived and understood in light of the idea. What is destructed by innovation, according to Plato, has to be sought at the ontological level of the idea as measure for the established political order, and not at the ontic level of things in the world (Blok 2020).

This also becomes clear in Plato's Republic. Here, Plato argues that the state should be ruled by the philosopher king, who has the necessary training and education that enables him to intellectually grasp ethical notions such as the idea of justice, and has the insights that are required to safeguard the political order. Here the problem with innovation becomes clear. If innovation transgresses the established political order of the world, it primarily intervenes at the level of the ideai, categories or values within which the world functions as order. Innovations are primarily disrupting the existing ideai, and consist in the human construction and introduction of new ideai. This means that the destructive aspect of innovation does not concern primarily the ontic level of things in the world, but the ontological level of the ideai, categories or values that establish and safeguard a world order. The idea that innovation primarily intervenes at the ontological level of the world order is also confirmed by a later writer on innovation, Francis Bacon, who argues that innovations "have altered the whole face and state of things right across the globe" (cited in Godin 2015, p. 182; Blok 2020).

Also in modern conceptions of innovation, what is at stake is not primarily the innovation of a new artefact from the earliest age to maturity, but the destruction of existing markets and construction of new markets for instance (Schumpeter 1943). What is destructed in the innovation of streaming services is not so much the $\mathrm{CD}$ in the literal sense of the word - there are still CDs in the world - but the way value is created and captured via markets in the economic order associated with digital networks like the Internet. What is destructed is not so much an artefact, but the political-economic order that is associated with, for instance, water and the way in which the water mill and the accompanying textile industry was embedded, which in turn gave rise to a new political-economic order associated with steam (railway industry for instance), digitalization and so on.

We see here that innovation operates at two levels of outcomes. The innovation of streaming services concerns first of all the ontogenesis of this service at an ontic level, but secondly the ontogenesis of the political-economic order of the world associated with digital networks 
at the ontological level. With 'ontology', we do not mean an eternal metaphysical idea, but a temporary category or value that establishes a particular political-economic order of the world - that is, the digital world - that enhances the invention of particular products or services - that is, streaming services - while it makes others obsolete - that is, the LP and CD. To the extent that innovation does not only concern new artefacts but also the structures within which these artefacts appear and are understood as ordered, we think that the distinction between the ontic and the ontological level of thinking may be helpful to understand the phenomenon of innovation. In the current age, the ontological level of innovation concerns the ontogenesis of a world order associated with digital networks, in which the streaming services can emerge, can be applied in various software applications and social media, and can be adopted and used by humans. This distinction between the ontic and ontological level of the innovation outcome provides a new perspective on the nature of innovation. Innovations like the internal combustion engine are innovations at the ontic level of the creation of a new artefact - the first engine for instance - but they involve at the same time the destruction of the economic equilibrium or world order associated with a particular set of innovations, in this case innovations associated with the world of steam. Simultaneously, the innovation of the internal combustion engine at an ontic level gives primarily rise to a new world order associated with electricity. The innovation outcome therefore doesn't only concern things in the world, but the world order in which these things appear and can be understood (Blok 2020). It is at this ontological level that innovation can be said to change the 'rules of the game' or the 'face of the Earth'. We argue therefore for a dual concept of the innovation outcome: innovation primarily operates at the ontological level of categories that constitute and establish a world, next to its operation at the ontic level within this world where it engenders novel things or innovative outcomes.

This duality doesn't mean that both levels are completely separated. The ontic and ontological levels of innovation turn out to be interconnected and interdependent. On the one hand, the innovation of the internal combustion engine at the ontic level is dependent on a world order associated with electricity. On the other hand, this world of electricity at an ontological level emerges only as world order in case of the innovation of the internal combustion engine that changes the rules of the game and destructs the world of steam. The innovation of the internal combustion engine articulates in a way the condition of its own possibility, namely the creation of the world of electricity as a regime in which this combustion engine can only function in a proper way and conditions further incremental improvements of this artefact; an innovation of the engine that doesn't take the boundary conditions of the world of electricity into account wouldn't make any sense. The innovation of the world of electricity is ontologically first, but not necessarily in the temporal sense of the word.

The interdependency of the innovation outcome at ontic and ontological level already provides good reasons to reject any unilateral focus on either the ontological level of innovation - we can think of a Heideggerian onto-centrism that highlights the importance of the ontological level of the innovation of a world order while neglecting the ontic level of innovations like the Internet, social media and so on - or on the ontic level of innovation - we can think of a post-phenomenological approach that highlights how the innovation of Google glass for instance mediates the world we experience. Roughly speaking, while Heidegger argues in his Question concerning technology that this ontological level of technology cannot be found at the level of screws and bolts of an artefact, Verbeek would argue that there is no ontological level beyond the screws and bolts of the artefact (Verbeek 2005). In fact, our reflections on the innovation outcome compel us to rehabilitate the ontic-ontological difference that was 
Table 20.1 Four characteristics of the phenomenon of innovation

\begin{tabular}{ll}
\hline Innovation Outcome: & Innovation Outcome: \\
artefact (Ontic Level) & world (Ontological Level) \\
\hline Innovation Process: & Innovation Process: \\
ontogenetic process in which an artefact emerges out of & ontogenetic process in which a new world emerges (Ontological \\
predecessors (Ontic Level) & Level) \\
\hline
\end{tabular}

rejected by post-modernist philosophy - for example, Ihde's idea that there is no Heideggerian 'essence' of technology beyond the many technologies (Ihde 2010) - at least in case we want to reflect on the phenomenon of innovation.

This dual concept of innovation has certain advantages over established dichotomies like radical and incremental innovation. While the distinction between incremental and radical seems to be only a gradual distinction that doesn't make clear what criterion has to be fulfilled for an innovation in order to be called radical, our conceptualization of the ontic and ontological level of innovation helps to operationalize this distinction; while incremental innovation concerns innovations only at an ontic level - a new version of the iPhone - radical innovation concerns innovations both at the ontic and ontological level which involves both the innovation of the steam engine and of the world of steam.

In Table 20.1, we summarize the findings of our reflection in this section. We first distinguished between the process and outcome dimension of innovation and then between the ontic and ontological dimension of innovation. These dimensions provide two axes that enable us to distinguish four characteristics of innovation, namely innovation as innovation outcome at the ontic level, like the innovation of streaming services; innovation as innovation outcome at the ontological level, like the political-economic order of the world - that is, the digital world - associated with digital networks in our current age; innovation as innovation process at the ontic level, like the process in which streaming services evolve out of predecessors (LPs, CDs) and the existing retail market for CDs is destructed and replaced; innovation as innovation process at the ontological level, like the process in which the digital world evolves out the world of petrochemicals and electricity (Blok 2020). A full understanding of the phenomenon of innovation encompasses these four characteristics of innovation.

\section{CRITICAL ASSESSMENT OF THE NEWNESS, THE TEMPORALITY AND THE HUMAN INVOLVEMENT IN INNOVATION}

These four characteristics of the phenomenon of innovation have several implications for our understanding of the object of innovation and the novelty involved, as well as for the temporality and human creativity involved in innovation practices.

In the previous section, we introduced a dual concept of the innovation outcome at the ontic and ontological level while traditionally, innovation is located on the ontic level of new artefacts, ranging from computers to nanotechnological instruments. We broadened our perspective to the innovation of a world order, that is, the innovation of a unifying principle in light of which the world appears as order, in which the innovation of particular artefacts can emerge. Such a unifying principle may be found in a new material resource or element - for example, electricity, steam, digitalization - that articulates for instance the digital world as condition for the possibility of the invention and use of new artefacts like sensing or blockchain technolo- 
gies that establish the digital world, but also in new concepts and new meanings of concepts like freedom, rationality and so on (Godin 2015, pp. 30-1).

The outcome of the innovation process is traditionally seen as the new. Newness can be seen as one of the key distinguishing factors between technology and innovation (Blok 2020); technology is associated with a type of knowledge which is contrasted with disruptive innovations which are associated with the un-known and concerns something new to the world. At the same time, newness and innovation are two separate things. On the one hand, everything we encounter in the world today was once new. On the other hand, the newness of many innovations we encounter in the world can be questioned and rather concern changes or improvements of what is already available in the world. This observation does not necessarily lead to the rejection of newness as distinguishing characteristic of innovation, but makes clear why a further reflection on the newness involved in innovation is needed.

The newness of the innovation outcome is not restricted to something new to the world, like the first combustion engine or the first flat screen TV as we have seen. Already in the literature on innovation management, a distinction is made between innovations that are new to the world and innovations that are only new to the firm. All kinds of gradual differences between categories of new products are acknowledged, ranging from improvement to repositioning and from incremental innovations to disruptive innovations (Christensen 1997). In the literature on invention for instance, innovations are seen as combinations or recombinations of things that already exist, or even a revisit of ancient things (Godin 2019). Also, from a historical perspective, we have to put the newness of the innovation outcome between brackets.

The concept of innovation originates from Ancient Greece, where it is named kainotomia. Kainotomia means change or the introduction of something new. It comes from kainon (new) and tom (cut, cutting) and originally meant 'cutting fresh into'. It was originally used in the context of the opening of new mines (Godin 2015, p. 19). Although Plato for instance is opposed to innovation because its newness disrupts the political order and can lead to revolution, the newness of innovation is often understood as renewal or reformation of the original; re-newal stresses newness as return to or as a taking back into an original situation (Godin 2015). This shows that the outcome of innovation is in first instance not something completely new to the world without any predecessor, as is sometimes said in case of disruptive innovations like the Internet, the combustion engine etc. The innovation outcome is the product of a historical process of renewal, in which this outcome emerges out of a previous stage and remains embedded in it in its future development. The innovation outcome may therefore consist in a repetition of an original state, or in the transformation of the current state (renovation) or in the renewal in a completely new state.

Such an ambiguous conceptualization of the new in innovation is problematic only if we conceptualize innovation based on its outcome on the ontic level. Then we are looking for a unique characteristic of the innovative product or service as outcome of innovation that didn't exist before and can be protected via patents. Such a unique characteristic will always remain contestable however if we acknowledge that all innovations emerge and evolve out of a previous historical stage and remain embedded in it. How to decide for instance whether the computer is new to the world or the combination of a typewriter and a TV?

Seen from the perspective of our earlier reflections on innovation as process, however, we can conceptualize the new in terms of the process of repetition, renovation, renewal, revolution and so on. The new then concerns the process of repetition, renovation, renewal that characterizes the ontogenetic process from pre-individual to individual, and that results 
in an innovation outcome that is revolutionary - it overthrows the established world order and is initiates a new beginning of a new world order. This newness of the world concerns a new organizing principle - the digital world - that co-evolves with artefacts that establish this world - sensing technologies, blockchain technologies, artificial intelligence and so on - that could not be expected or anticipated from the worlds that were before; in the world of electricity, innovations like blockchain could not yet be imagined. Innovations concern the absolute new beginning of a world that cannot be expected upfront but that is not detached from history but remain embedded in the temporal dimension of past, present and future. Seen from the perspective of the ontogenetic process of innovation, the newness of the innovation outcome consists in its break with the past (discontinuity) on the one hand, which remains embedded in the history it emerges from (continuity) in its future development on the other. In this respect, we can conceptualize the new involved in innovation in terms of the unexpected and un-known that cannot be calculated upfront, but is an eruption that is born in a world and that constitutes a world.

With this, we receive a further characteristic of the innovation process. The new that is at stake in the process of innovation is characterized by iterability (cf. Derrida 1982), that is, by the paradoxical simultaneity of sameness and otherness. Or framed in terms of the ontogenetic process: to the extent that innovations always remain embedded in the history they emerge from, the 'new' of innovation is always less than itself (pre-individual) and to the extent that the 'new' of innovation always involves a break with this past and is on its way to a possible future, it is always more than itself (post-individual). We see here that the ambiguous notion of newness is less problematic if we conceive it from the perspective of the process of innovation. The new as outcome of innovation is not only not a unique characteristic of this outcome but embedded in an iterative process of repetition and renewal. With this, the new is also not created ex nihilo or 'out of the blue' but determined by the temporal dimension of innovation it emerges from as ontogenetic process; the new is the individual outcome of the innovation process at the pre-individual level, that is, conditioned by (temporal) iterability.

The idea of the new as outcome of the innovation process at a pre-individual level seems to be at odds with two of the fundamental assumptions in contemporary thinking about innovation: (1) that innovation is not so much the outcome of a historical process, but the product of human creativity; (2) that human actors at an individual level are the subject of innovation. According to Schumpeter for instance, the innovator is a very special type of disruptive person. Also, the OECD and the EU see the human actor (businessmen, entrepreneur) as the primary subject of innovation. ${ }^{3}$

Seen from the perspective of the history of innovation, however, it is not self-evident that the human actor is the subject of innovation in this double sense of the word. In the ancient and medieval reflections on innovation, the human actor is not yet seen as the subject of innovation, nor necessarily as the creator of innovation (Godin 2015, p. 66). Seen from the Platonic perspective we discussed before, the human construction of a new idea should be rejected, first, because the transcendent world of the ideai is fixed and eternal and cannot be replaced by new ones according to Plato. Second, human being does not consist in the construction of new ideai (we can associate this with the vita activa), but should be enabled to grasp the eternal ideai to safeguard the political order in light of this idea (we can associate this with the vita contemplativa) (Blok 2020).

Also in case of Machiavelli for instance, the human actor is not yet seen as the subject of innovation. Not human being is the initiator of the innovation process, but time itself; time is 
seen as corrupting the established world order that calls for innovation as intervention to withstand this corruption (Blok 2020). A similar idea can be found in the work of Francis Bacon: "Surely every medicine is an innovation; and he that will not apply new remedies, must expect new evils; for time is the greatest innovator; and if time of course alter things to the worse, and wisdom and counsel shall not alter them to the better, what shall be the end?" (cited in Bontems 2014, p. 43). Time itself is seen here as innovator, namely destructing the established world order, that at the same time calls for innovations that withstand this corruption and construct and safeguard a newly established world order.

Seen from this perspective, we can conceptualize the destructive dimension of innovation as entropic aspect of the innovation process, while the creative dimension of innovation can be conceived as a negentropic aspect of the innovation process. ${ }^{4}$ To be sure, it is not the case that time is entropic, and innovation is negentropic; the ontogenetic process of innovation is both characterized by an entropic aspect and a negentropic aspect at the pre-individual level, where the interplay of entropy and negentropy constitutes new individual innovation outcomes. The confrontation between the entropic and negentropic aspect of the innovation process makes clear that the temporal iterability of the innovation process cannot be understood in a chronological way. While the initiation of the innovation outcome could still be understood in a chronological way, namely as embedded in the history it emerges from and the futural state toward which it develops, the entropic and negentropic dimensions of the temporal iterability of the innovation process show that the initiation of the new (innovation outcome) is temporal but can no longer be understood in a chronological way. ${ }^{5}$

We continue to ask for the role of the human actor in the ontogenetic process of creating the 'new'. Although our findings regarding the innovation process indicate a decentralization of the (human) subject, this doesn't imply that the human actor has no role anymore in the innovation process. In ancient times already, innovation is associated with changes by humans, as opposed to changes by God (Godin 2015); the innovator is the one who intervenes in the established political order, who is a violator of boundaries and a dissenter (Godin 2015). And although empirical research on the question whether opportunities for new innovations are objective or not is still inconclusive (cf. Kirzner 1997), it is nowadays assumed that opportunities for innovation emerge in the structural interrelation between 'subjective perception' and 'objective realities' (Gregoire et al. 2010; cf. Ploum et al. 2017). Also in the sociological literature on innovation systems, the co-constructive role of the human actor is highlighted (Geels 2005). So although the human actor is not the primary subject of innovation, he is definitely included in the innovation process and has a role in it. How do we have to conceptualize the involvement of human being in the innovation process?

Let's turn to the history of innovation for a moment to receive an answer to this question. In the Bible for instance, we encounter innovation in terms of the metamorphosis of human existence that is needed according to Paulus, the renewal of the spirit in becoming Christian (Godin 2015). When Paulus for instance calls for a renewal of the spirit to become a true Christian, he doesn't call primarily for a change in our actual behaviour, but for a change of our identity as humans, namely, to become a true Christian. Also in other ancient sources, innovation is associated with 'renewing the soul' (Godin 2015, p. 217). A first sense of the human includedness in the innovation process emerges if we consider that the identity of human being can be the object of innovation.

A second sense of inclusion emerges if we consider such a metamorphosis to the Christian as ontogenesis of this innovation outcome. In this case, the idea of human being as Christian 
is the outcome of the innovation process. But this implies that human being as Christian is not the subject of innovation. To the extent that human being as Christian is an individual outcome of the innovation process, the role of human agency in the innovation process has to be conceived at a pre-individual level; the human actor that is involved in the metamorphosis to human being as Christian (individual innovation outcome) is himself not a Christian yet, but underway to a possible futural state in this ontogenetic process (pre-individual). To the extent that the metamorphosis to the Christian only succeeds with a certain human co-creation at the pre-individual level to be constituted at the individual level, human existence is involved in the ontogenetic process of innovation.

This human co-creation in the innovation process is not only at stake in case humans are the object of innovation, that is, in case of a renewal of the soul. In fact, human being is always already involved in the innovations that establish the world order. Why? The innovation of the steam engine changes not only the order of things in the world (the emergence of textile industry). To the extent that human being is always already intentionally involved in a meaningful world (Heidegger 2008), the innovation of the steam engine includes at the same time our human responsiveness to the world of steam, as user, adopter, operator, disseminator and so on of this innovation. The innovations that establish a new world order concern the human-world relation as a whole.

Seen from this perspective, human being is not only the co-creator in the ontogenetic process of innovation at the pre-individual ontic level, but also the outcome of this process, namely as the adopter and disseminator of this innovation within the newly established world order at an individual ontic level, for instance as early adopter (Rogers 1962). ${ }^{6}$ This means that human agency occurs at two places in the ontogenetic process of innovation:

(1) Human being can be seen as involved in the ontogenetic process as pre-individual co-creator that contributes to the innovation outcome. In the context of this chapter, we can conceptualize the human co-creativity at the pre-individual level only in a negative way: a) human co-creativity has to be thought at the pre-individual ontic level, and not at the level of the individual input (human as subject) or the output (human as adopter) level of this process; b) human co-creativity at a pre-individual ontic level contributes to the ontogenetic process at pre-individual ontological level, and has to be understood therefore out of the ontogenesis of the new. This leaves open the question how the co-creativity of human being at the pre-individual level has to be conceived in a positive way. ${ }^{7}$

(2) Human being can be seen as involved in the outcome of the ontogenetic process as adopter of the innovation that establishes a new world order. The new world order is only established thanks to the human adoption and dissemination of this innovation. This contribution doesn't make him the subject of innovation either, because this contribution primarily consists in the adoption of the innovation.

This double role of human being in innovation opens a new perspective on the classical idea that innovation is the creation of something new and its adoption by the market. While creation as such may still be associated with art, innovation is at stake if the creative act of innovation is accompanied by its adoption. Here, we see these two aspects of innovation represented in the two roles of human being at the individual and the pre-individual level. The question remains how the two roles of human agency as co-creator in the innovation process and as adopter are related to each other. 
Table 20.2 Four characteristics of the phenomenon of innovation and its implications for the novelty, temporality and human involvement in innovation practices

\begin{tabular}{|c|c|c|}
\hline & Ontic level & Ontological level \\
\hline Innovation Outcome & $\begin{array}{l}\text { Individual innovation outcome at an ontic level: } \\
\text { 'new' individual components and compositions of } \\
\text { components in individual products or services, like } \\
\text { the innovation of streaming services, and human } \\
\text { being as adopter of these innovation outcomes. }\end{array}$ & $\begin{array}{l}\text { Individual innovation outcome at an ontological } \\
\text { level: a 'new' political-economic world order, like } \\
\text { the one associated with digital networks, which } \\
\text { accompanies the emergence of new products and } \\
\text { services within this new world order, like streaming } \\
\text { services. }\end{array}$ \\
\hline Innovation Process & $\begin{array}{l}\text { Ontogenetic process at pre-individual ontic level, in } \\
\text { which innovation outcomes like steaming services } \\
\text { emerge iteratively out of predecessors, in which the } \\
\text { human co-creative capacity is involved. }\end{array}$ & $\begin{array}{l}\text { Ontogenetic process at pre-individual ontological } \\
\text { level, in which for example the digital world evolves } \\
\text { out of the negentropic (creative) and entropic } \\
\text { (destructive) dimension of temporal iterability, and } \\
\text { in which the human co-creative capacity is involved. }\end{array}$ \\
\hline
\end{tabular}

In Table 20.2, we summarize the findings of our philosophical reflections on the concept of innovation in this section, and its implications for our understanding of the object of innovation and the novelty involved, as well as the temporality and human involvement in innovation.

\section{CONCLUSION}

In this chapter, we challenged the techno-economic paradigm of our understanding of innovation, building on earlier work (Blok 2020, 2021), in order to articulate a philosophy of innovation. We opened up the phenomenon of innovation by distinguishing between the innovation process and outcome dimension and between the ontic and ontological dimension of innovation.

We showed that established theories of innovation in economics and business administration often focus on the innovation outcome, which enables to distinguish between incremental and radical innovation, while they omit particular reflections on the nature of the innovation process itself. Contrary to theories of innovation that conceptualize the process of innovation based on its outcome, for instance the distinction between closed and open innovation, we articulated the ontogenetic process of innovation in this chapter. The first contribution of the philosophy of innovation is the alternative conceptualization of the innovation process as a pre-individual ontogenetic process. It helps alternative theories of innovation to criticize the superficial conceptualization of innovation processes in stage-gate and technology assessment models, and enables us to reflect on the innovation process of creation and destruction as distinct from the innovation outcome. We provided the example of the process of concretization at stake in innovation that cannot be attributed to the input or output of innovation.

We also showed that established theories of innovation often focus on the innovation outcome at an ontic level - for example the iPhone or the steam engine - while they omit to reflect on the world order involved - for example the world of steam - that is for instance destructed by the invention of the internal combustion engine and creates for instance the world of electricity. This is strange, as we have seen that economists like Schumpeter already indicated the role of economic waves in innovation, while other disciplines indicated the role of structural socio-technical changes. The second contribution of the philosophy of innovation 
consists in a philosophical perspective on the role of waves and changes in innovation, and in an alternative conceptualization of the innovation outcome as a combination of an outcome at the ontic and ontological level; the innovation of the steam engine requires the innovation of the world of steam, while it at the same time establishes this world of steam. This dual concept of the innovation outcome helps to criticize the often naïve and superficial conceptualization of the innovation outcome as incremental or radical innovations, and enables alternative theories of innovation to take the innovation outcome at the ontological level into account in further theoretical developments. With this, we also contribute to contemporary debates in philosophy of technology, which focus on either the ontic or ontological level of innovation and technology, while we highlighted the interdependency and interconnectedness of the ontic and ontological level of technology and innovation.

The third contribution of the philosophy of innovation is the provision of a criterion to distinguish between incremental and radical innovation. While this distinction in innovation theory is criticized because it seems to be conventional or at least arbitrary, we propose a clear criterion based on the philosophy of innovation: incremental innovations concern innovations at an ontic level only, while radical innovations concern innovations which involve both the ontic and ontological level.

We then sketched several implications of the philosophy of innovation for our understanding of the object of innovation and the novelty involved, as well as for the temporality and human involvement in innovation practices. If innovation concerns an ontogenetic process in which primarily a world is constituted - that is, the digital world - in which the invention of new artefacts - that is, an Artificial Intelligence application - is embedded, we should consider new developments from this perspective. We should primarily ask for the world order that may be created by these new types of innovation, and how these innovations challenge our current way of living together in the world. The advantage of our philosophy of innovation is that it enables future research to broaden its perspective from the ontic level of the innovation outcome of individual innovations to the ontological level of the political-economic world order that is created and destructed by these new types of innovation.

Although we have seen that the innovation outcome can be seen as something new, the newness involved in innovation is not so much associated with the innovation outcome at an ontic level, as it is here that the newness of new artefacts can always be questioned. On the contrary, it is primarily connected with the new world order that it establishes. This new world order is not the product of a creation ex nihilo, but remains embedded in the historical process in which it emerges as repetition, renewal, reformation, revolution; it overthrows the established world order and initiates a new beginning of a new world order. In this respect, the new involved in innovation practices concerns an absolute new beginning of a world that cannot be expected upfront (discontinuity), but is not detached from history and remains embedded in the temporal dimension of past, present and future (continuity). This ontogenetic process doesn't follow a chronological temporal order, but is constituted by a temporal iterative process. The fourth contribution of the philosophy of innovation is that it moves beyond the traditional opposition between linear and circular innovation models in innovation management, and highlights the iterability or simultaneity of sameness and otherness involved in innovation. It also moves beyond the traditional idea of human being as creative actor and primary subject of innovation and highlights the human involvement in the temporal iterability of this ontogenetic process of historical development itself, in which the established world order is overthrown (entropy) and a new beginning of a new world order is initiated (negentropy). Human creativ- 
ity is involved in this ontogenetic process as co-creative capacity, namely human identity as an ontological outcome of innovation and at the same time human identity as pre-individual involvement in the process of innovation. The advantage of the philosophy of innovation is that it enables future research to broaden its perspective from the human actor as creator and subject of innovation to the world building capacity of human being, as it is conceptualized in the philosophical tradition (Arendt 1958).

The potential strengths of our philosophy of innovation consists in its ability to move beyond the techno-economic paradigm and to broaden our perspective on the phenomenon of innovation. Although much more dedicated research is needed to analyse its advantages and disadvantages in the context of contemporary developments like social, sustainable and responsible innovation, the philosophical reflections on the concept of innovation we developed in this chapter provide already clear contributions to the further development of our understanding of this challenging phenomenon. It also enables dedicated reflections on the ethics of innovation beyond the techno-economic paradigm, that concentrate on innovation as human ethos (Blok 2018).

\section{NOTES}

1. In the philosophical tradition, ontogenesis refers to the process in which not a new being - e.g. a particular computer - emerges, but the being of this new being - e.g. the invention of the first computer, which involved the first computer both at an ontic and an ontological level-emerges.

2. Parts of this section are earlier published in Blok (2021).

3. This also explains the huge amounts of public investments in entrepreneurship education both in the developed and developing world, support of start-ups at technical universities, etc.

4. Negentropy is defined as the opposite of entropy, and means that the innovation process not only destructs the established world order (entropy), but also constructs a new established order (negentropy).

5. The further reflection on the temporal dimension of the ontogenetic process of innovation is beyond the scope of this chapter because the temporality of innovation is not a reinvention of the old (chronological time) and requires a new philosophy of history, in which no longer a dualism between an active human creator and a passive materiality of the Earth is at stake, but both are interdependent and interconnected.

6. This idea philosophically substantiates the findings of Gabriel Tarde, who associates innovation not so much with invention and more with its adoption (cf. Tarde 1903).

7. It is this type of reflections on the nature of human co-creation, that are completely omitted in scientific literature on user-led innovations for instance (cf. von Hippel 2005).

\section{REFERENCES}

Arendt, Hannah (1958), The Human Condition, Chicago: Chicago University Press Aristotle (1944), Politics, Cambridge: Harvard University Press

Blok, Vincent, Lemmens, P. (2015), 'The emerging concepts of responsible innovation. Three reasons why it is questionable and calls for a radical transformation of the concept of innovation', in B. Koops, I. Oosterlaken, J. van den Hoven, H. Romijn and T. Swierstra (eds), Responsible Innovation 2: Concepts, Approaches, and Applications, Dordrecht: Springer International Publishing, pp. 19-35.

Blok, Vincent (2018), 'Innovation as ethos: Moving beyond CSR and practical wisdom in innovation ethics', in C. Neesham and S. Segal (eds), Handbook of Philosophy of Management, Dordrecht: Springer, pp. 1-14. 
Blok, Vincent (2020), 'Towards an ontology of innovation: On the new, the political-economic dimension and the intrinsic risks involved in innovation processes', in N. Doorn and D. Michelfelder (eds), Routledge Handbook of Philosophy of Engineering (forthcoming), London: Routledge, pp. 273-85.

Blok, Vincent (2021), 'What is innovation? Laying the ground for a philosophy of innovation', Techné: Research in Philosophy and Technology, 25 (1), 72-96.

Bontems, Vincent (2014), 'What does Innovation Stand For? Review of a Watchword in Research Policies', Journal of Innovation Economics and Management, 3, 39-57.

Chesbrough, Henry (2003), Open Innovation: The New Imperative for Creating and Profiting from Technology, Boston: Harvard Business School Press.

Chesbrough, Henry (2006), Open Innovation: Researching a New Paradigm, Oxford: Oxford University Press.

Christensen, Clayton (1997), The Innovator's Dilemma: When New Technologies Cause Great Firms to Fail, Cambridge: Harvard Business Review Press.

Cooper, R.G. (2008), 'Perspective: The Stage Gate Idea to Launch Process - Update: What's New and Nexgen Systems', Journal of Product Innovation Management, 25 (3), 213-32.

Derrida, Jacques (1982), Margins of Philosophy, Chicago: University of Chicago Press.

Freeman, Christopher and Luc Soete (1997), The Economics of Industrial Innovation, London: Continuum.

Geels, F. (2005), Technological Transitions and System Innovations: A Co-evolutionary and Socio-technical Analysis, Cheltenham, UK and Northampton, MA, USA: Edward Elgar Publishing.

Godin, Benoit (2008), Innovation: the history of a category (working paper no. 1).

Godin, Benoit (2015), Innovation Contested. The Idea of Innovation over the Centuries, New York: Routledge.

Godin, Benoit (2019), The Invention of Technological Innovation. Languages, Discourses and Ideology in Historical Perspective, Cheltenham, UK and Northampton, MA, USA: Edward Elgar Publishing.

Gregoire, D.A., P.S. Barr and D.A. Shepherd (2010), 'Cognitive Processes of Opportunity Recognition: The Role of Structural Alignment', Organization Science, 21 (2), 413-31.

Heidegger, Martin (2008), Being and Time, New York: Harper Collins Publishers.

Henderson, R.M. and K.B. Clark (1990), 'Architectural Innovation: The Reconfiguration of Existing Product Technologies and the Failure of Established Firms', Administrative Science Quarterly, 35, 9-30.

Ihde, D. (2010), Heidegger's Technologies. Postphenomenological Perspectives, New York: Fordham.

Kirzner, I.M. (1997), 'Entrepreneurial Discovery and the Competitive Market Process: An Austrian Approach', Journal of Economic Literature, 35 (1), 60-85.

Plato (1967), Plato in Twelve Volumes, Cambridge: Harvard University Press.

Ploum, L., Vincent Blok, T. Lans, O. Omta (2017), 'Exploring the Relation between Individual Moral Antecedents and Entrepreneurial Opportunity Recognition for Sustainable Development', Journal of Cleaner Production, doi: 10.1016/j.jclepro.2017.10.296 (in press).

Rogers, Everett M. (1962), The Diffusion of Innovations, New York: Free Press.

Rogers, Everett M. (1976), 'Where are we in the understanding of diffusion of innovations?', in W. Schramm and D. Lerner (eds), Communication and Change: The Last Ten Years - and the Next, Honolulu: University Press of Hawaii, pp. 204-22.

Schumpeter, Joseph (1943), Capitalism, Socialism and Democracy, London: Routledge.

Simondon, George (2017), On the Mode of Existence of Technical Objects, Minneapolis: Univocal Publishing.

Tarde, Gabriel (1903), Laws of Imitation, New York: Hold and Company.

Verbeek, P.P. (2005), What Things Do. Philosophical Reflections on Technology, Agency and Design, Pennsylvania: Pennsylvania State University Press.

von Hippel, Eric (2005), Democratizing Innovation, London: MIT Press

von Schomberg, Lucien and Vincent Blok (2018), 'The Turbulent Age of Innovation. Questioning the Nature of Innovation in Responsible Research \& Innovation', Synthese (in press). 